\title{
Double capping of molecular beam epixtaxy grown InAs/lnP quantum dots studied by cross-sectional scanning tunneling microscopy
}

\author{
Citation for published version (APA): \\ Ulloa Herrero, J. M., Koenraad, P. M., Gapihan, E., Létoublon, A., \& Bertru, N. (2007). Double capping of \\ molecular beam epixtaxy grown InAs/InP quantum dots studied by cross-sectional scanning tunneling \\ microscopy. Applied Physics Letters, 91(7), 073106-1/3. [073106]. https://doi.org/10.1063/1.2771063
}

DOI:

10.1063/1.2771063

Document status and date:

Published: 01/01/2007

\section{Document Version:}

Publisher's PDF, also known as Version of Record (includes final page, issue and volume numbers)

\section{Please check the document version of this publication:}

- A submitted manuscript is the version of the article upon submission and before peer-review. There can be important differences between the submitted version and the official published version of record. People interested in the research are advised to contact the author for the final version of the publication, or visit the DOI to the publisher's website.

- The final author version and the galley proof are versions of the publication after peer review.

- The final published version features the final layout of the paper including the volume, issue and page numbers.

Link to publication

\footnotetext{
General rights

- You may freely distribute the URL identifying the publication in the public portal. follow below link for the End User Agreement:

www.tue.nl/taverne

\section{Take down policy}

If you believe that this document breaches copyright please contact us at:

openaccess@tue.nl

providing details and we will investigate your claim.
}

Copyright and moral rights for the publications made accessible in the public portal are retained by the authors and/or other copyright owners and it is a condition of accessing publications that users recognise and abide by the legal requirements associated with these rights.

- Users may download and print one copy of any publication from the public portal for the purpose of private study or research.

- You may not further distribute the material or use it for any profit-making activity or commercial gain

If the publication is distributed under the terms of Article $25 \mathrm{fa}$ of the Dutch Copyright Act, indicated by the "Taverne" license above, please 


\title{
Double capping of molecular beam epitaxy grown InAs/InP quantum dots studied by cross-sectional scanning tunneling microscopy
}

\author{
J. M. Ulloa a) and P. M. Koenraad \\ eiTT/COBRA Inter-University Research Institute, Eindhoven University of Technology, P.O. Box 513, \\ NL-5600MB Eindhoven, The Netherlands \\ E. Gapihan, A. Létoublon, and N. Bertru \\ Laboratoire d'Études des Nanostructures Semiconductrices (LENS), INSA-Rennes, \\ F-35-43 Rennes Cedex, France
}

(Received 1 March 2007; accepted 22 July 2007; published online 15 August 2007)

\begin{abstract}
Cross-sectional scanning tunneling microscopy was used to study at the atomic scale the double capping process of self-assembled InAs/InP quantum dots (QDs) grown by molecular beam epitaxy on a (311)B substrate. The thickness of the first capping layer is found to play a mayor role in determining the final results of the process. For first capping layers up to $3.5 \mathrm{~nm}$, the height of the QDs correspond to the thickness of the first capping layer. Nevertheless, for thicknesses higher than $3.5 \mathrm{~nm}$, a reduction in the dot height compared to the thickness of the first capping layer is observed. These results are interpreted in terms of a transition from a double capping to a classical capping process when the first capping layer is thick enough to completely cover the dots. (C) 2007 American Institute of Physics. [DOI: 10.1063/1.2771063]
\end{abstract}

Self-assembled InAs/InP quantum dots (QDs) grown by the Stranski-Krastanow growth mode are attracting great interests from both physical and technological points of view. The main potential application of these structures is as the active region of high performance lasers emitting at $1.55 \mu \mathrm{m},{ }^{1-4}$ the long-range optical fiber communication wavelength. For that purpose, an accurate control of the emission wavelength and of the QD size distribution is of a crucial importance. One method to reduce the QD height dispersion is based on a discontinuous capping process, ${ }^{5}$ where the capping is performed in two sequences. First, a capping layer is deposited, with a thickness smaller than the QD height. Then, a growth interruption under phosphorous flux is performed, during which the uncovered part of the dots disappears due to As/P exchange, ${ }^{3,6}$ leading, in principle, to an uniform QD height equal to the thickness of the first thin capping layer. Finally, the capping layer growth is completed. This modified capping procedure, named double cap (DC), was shown to allow wavelength emission control and to drastically decrease the photoluminescence (PL) linewidth. ${ }^{5}$ Indeed, room temperature lasers based on doublecapped InAs/InP QDs with low threshold current density emitting close to $1.55 \mu \mathrm{m}$ were recently demonstrated on (311) $B$ substrates. ${ }^{4}$ On (100) substrates, the DC process was also used for device elaboration by metal organic vapor phase epitaxy (MOVPE). ${ }^{7}$ However, it has been recently observed that the preferential growth of the first cap layer occur on the edge of the QDs. This should induce an inaccurate control of the QD heights by the DC process in MOVPE. ${ }^{8}$

The initial stage of the capping process of InAs QDs is a very complex phenomenon, ${ }^{9-12}$ sensitive to many growth parameters. ${ }^{13,14}$ It has mainly been studied for InAs/GaAs QDs, ${ }^{9-14}$ and very little is known in the case of InAs/InP QDs, ${ }^{8,15-17}$ in which the As/P exchange reaction complicates the description. It is therefore difficult to know what happens during and after the deposition of the first capping layer in

\footnotetext{
${ }^{a)}$ Electronic mail: j.m.ulloa@tue.nl
}

the double capping method, and a detailed structural characterization of the process is required.

We have used cross-sectional scanning tunneling microscopy (X-STM) to study the double capping process of InAs/InP QDs grown by molecular beam epitaxy (MBE) at the atomic scale. The effect of first cap layer with different thicknesses and composition has been analyzed.

The samples were grown by gas source $\mathrm{MBE}$ on a $\mathrm{Si}$ doped (311) $B$ oriented InP substrate. The growth temperature was set to $480{ }^{\circ} \mathrm{C}$. The QDs were formed by depositing 2.1 (100) equivalent monolayers of InAs both on InP and $\mathrm{In}_{0.87} \mathrm{Ga}_{0.13} \mathrm{As}_{0.285} \mathrm{P}_{0.715}$ (lattice matched to $\mathrm{InP}$ ) buffer layers. In order to ease the analysis, a high As beam equivalent pressure was supplied to the surface during the InAs deposition in order to favor the formation of large QDs. ${ }^{18}$ After island formation, a $30 \mathrm{~s}$ growth interruption under As flux was performed before the growth of the capping layer. Then, the first capping layer (CL1) was deposited and the growth was interrupted for $60 \mathrm{~s}$ maintaining a group $\mathrm{V}$ overpressure. Finally, a thick (50 or $100 \mathrm{~nm}$ ) second capping layer (CL2) was grown. Three different samples were studied. In sample A, three QD layers were grown with different thicknesses of CL1: $1.5,2.5$, and $3.5 \mathrm{~nm}$ (from now on called layer 1, layer 2 , and layer 3, respectively). The buffer and the capping layers consisted of $\operatorname{In}_{0.87} \mathrm{Ga}_{0.13} \mathrm{As}_{0.285} \mathrm{P}_{0.715}$. In sample $\mathrm{B}$, the buffer, CL1 and, CL2 were made of InP. Finally, in sample $\mathrm{C}$, the buffer and CL2 were made of InP, while CL1 consisted of $\operatorname{In}_{0.87} \mathrm{Ga}_{0.13} \mathrm{As}_{0.285} \mathrm{P}_{0.715}$. In samples $\mathrm{B}$ and $\mathrm{C}$, four QD layers were grown with different thicknesses of CL1: 2, 3,4 , and $5 \mathrm{~nm}$ (layers 1, 2, 3, and 4, respectively).

The X-STM measurements were carried out on the [0-11] surface plane of in situ cleaved samples under UHV ( $p<4 \times 10^{-11}$ Torr) conditions by using polycrystalline tungsten tips. The images of the QDs and of the capping layers were obtained in constant current mode during which both the topography and current images were recorded simultaneously. All the images shown are taken at high negative voltage $(\sim-3.0 \mathrm{~V})$. Under these conditions the elec- 


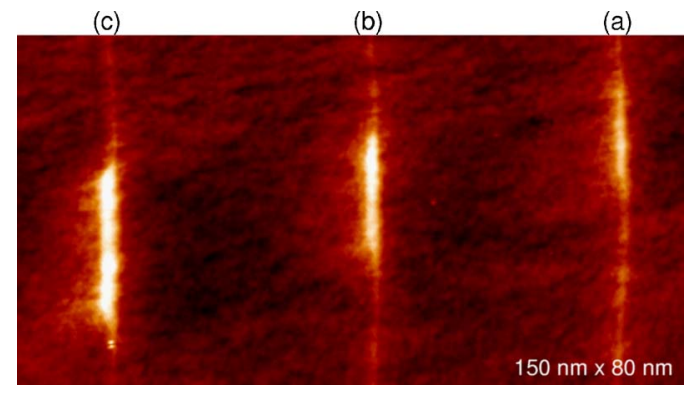

FIG. 1. (Color online) Large scale filled states image of sample A showing the three QD layers in which CL1 is 1.5, 2.5, and $3.5 \mathrm{~nm}$ thick in (a), (b), and (c), respectively. The growth direction is from right to left. $V_{\text {sample }}=-2.5 \mathrm{~V}$ and $I_{\text {tunnel }}=50 \mathrm{pA}$.

tronic contrast is strongly suppressed and the measurement reflects mainly the topographic contrast. ${ }^{19}$

First, we present results on sample A, with InGaAsP buffer and capping layers. Figure 1 shows a large scale filled states image of this sample. The three QD layers separated by $\sim 50 \mathrm{~nm}$ are observed. The inhomogeneous contrast in the buffer and capping layers is due to the random alloy fluctuations in the InGaAsP. Remarkably, the QDs have a very large base length. The maximum measured base length was $60 \mathrm{~nm}$, which gives aspect ratios as low as 0.04 . It is clear from Fig. 1 that the height of the QDs increases when the thickness of CL1 increases. Moreover, the height of the QDs in each layer fits very well with the nominal thickness of CL1. After analyzing 37 dots in this sample, the measured average height in layer $1 \quad(C L 1=1.5 \mathrm{~nm})$ was $1.6 \mathrm{~nm}$, in layer $2(\mathrm{CL} 1=2.5 \mathrm{~nm}) 2.5 \mathrm{~nm}$, and in layer 3 $(\mathrm{CL} 1=3.5 \mathrm{~nm}) 3.4 \mathrm{~nm}$ (see the triangles in Fig. 4). This indicates that the double capping procedure is controlling the QD height with high accuracy.

In sample B, buffer and both capping layers consist of InP and the thickness of CL1 was increased up to $5 \mathrm{~nm}$. Fig. 2 shows the current image of one dot in layer 2 of this sample. On such specific QDs, shallow trenches in the InP buffer close to the QDs are observed. We assume that the trenches are mainly formed just after the dot formation during the growth interrupt under As pressure. Mass transport from wetting layer to quantum dots leads to the formation of dewetted InP surface on which As/P exchange reaction occurs. The extra InAs formed due to As/P exchange migrates to the dots and a trench is formed around the QDs. The fact that these trenches were not present in sample A (see Fig. 1), where the dots were grown on InGaAsP, supports this explanation (As/P exchange is reduced on an InGaAsP surface). ${ }^{16}$ Similar observations have been previously reported for InAs

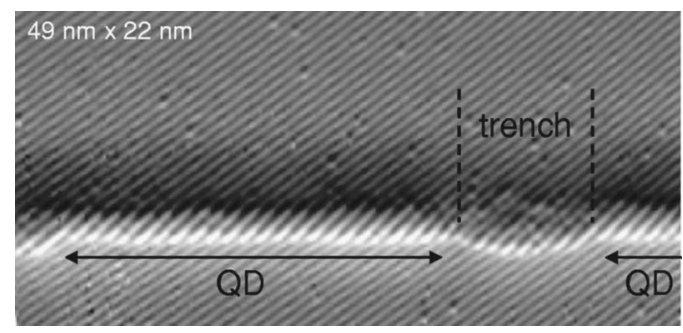

FIG. 2. Current image of a QD in sample B corresponding to layer 2 $(\mathrm{CL} 1=3 \mathrm{~nm})$. Part of a second QD appears on the right and a shallow trench is clearly observed between the two QDs. $V_{\text {sample }}=-2.5 \mathrm{~V}$, and $I_{\text {tunnel }}$

=52 pAsly observed for large InGaAs QDs on GaAs, may be ef-
Downloaded 26 Feb 2008 to 131.155.108.71. Redistribution subject to AIP license or copyright; see http://apl.aip.org/apl/copyright.jsp

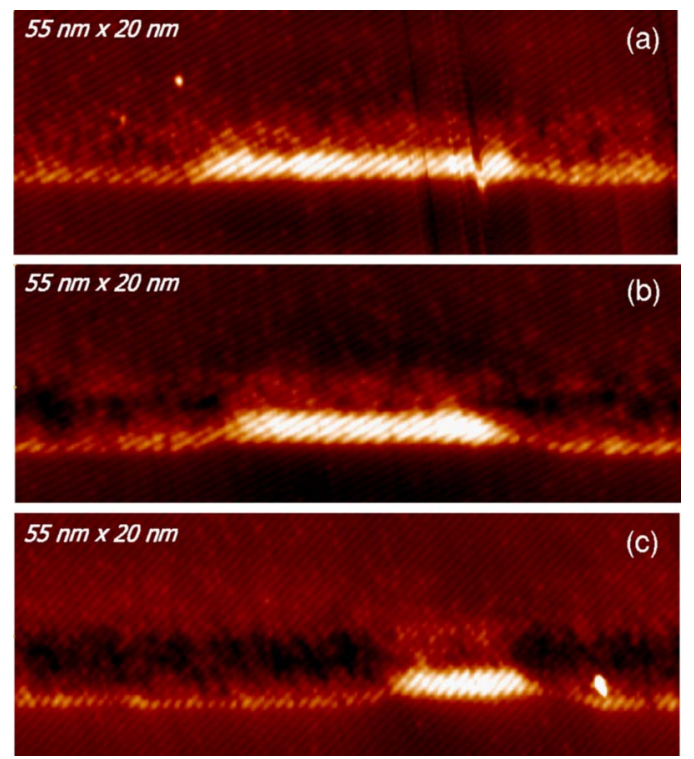

FIG. 3. (Color online) Topography image of three QDs in sample C corresponding to (a) layer $1(\mathrm{CL} 1=2 \mathrm{~nm})$, (b) layer $3(\mathrm{CL} 1=4 \mathrm{~nm})$, and (c) layer $4(\mathrm{CL} 1=5 \mathrm{~nm})$. CL1 appears as a dark region between the WL and CL2. The bright spots are As atoms in the $P$ matrix. $V_{\text {sample }}=-3.0 \mathrm{~V}$ and $I_{\text {tunnel }}=53 \mathrm{pA}$.

QDs grown on (001) InP, and explained in a similar way. ${ }^{20}$

Figure 2 is representative of what was observed when CL1 was 2 or $3 \mathrm{~nm}$ thick. The dots are similar to the ones in sample A: they have a flattop facet and their height fits very well with the thickness of CL1 (the average heights were 2.2 and $2.9 \mathrm{~nm}$ in layers 1 and 2, respectively). Nevertheless, the situation is different when CL1 are 4 and $5 \mathrm{~nm}$ thick. In this case, the measured average heights of the QDs are 3.1 and $4 \mathrm{~nm}$, respectively. Thus the QD heights are not accurately controlled by the first cap layer thickness in this range. These results confirm the PL measurement as a function of the thickness of CL1 previously published. ${ }^{5}$ For CL1 thicker than $4 \mathrm{~nm}$, the PL energy control by the DC process is lost.

In sample C, CL1 and CL2 consist of InGaAsP and InP, respectively. The thicknesses of CL1 were set at 2, 3, 4, and $5 \mathrm{~nm}$. Figure 3 shows a filled states topography image of layers 2, 3, and 4. Atomic details are resolved in this image, in which the group $\mathrm{V}$ elements, i.e., As and $\mathrm{P}$, are imaged. As the QDs are grown on InP, the trenches are present again, but it is clear from image 3 (c) that it is a global effect affecting the whole WL. CL1 appears as a dark region with inhomogeneous contrast between the wetting layer (WL) and (CL2). A bright region in CL1 on top of the QDs is observed in layers 3 and 4, indicating an As and/or In rich region. This is likely due to strain induced composition modulation, as shown in Ref. 16 The thicknesses of CL1 in layers 2, 3, and 4 , measured from the top of the WL, are 2.9, 3.8, and $4.8 \mathrm{~nm}$, respectively. This is in good agreement with the nominal values. Figure 3(a) shows how in layer 2 the height of the QD is leveled to the thickness of CL1. This is also the case in layer 1 (not shown). As in the previous sample, when the thickness of CL1 is increased to $4 \mathrm{~nm}$, the height of the QDs is slightly smaller than CL1 [see Fig. 3(b)]. This difference is much bigger when CL1 is $5 \mathrm{~nm}$ thick. In this case the height of the QD is more or less half of the thickness of CL1, as shown in Fig. 3(c). Moreover, a strong decrease of the QD density is observed in this layer. Island dissolution, as previously observed for large InGaAs QDs on GaAs, may be ef-
O AIP license or copyright; see http://apl.aip.org/apl/copyright.jsp 


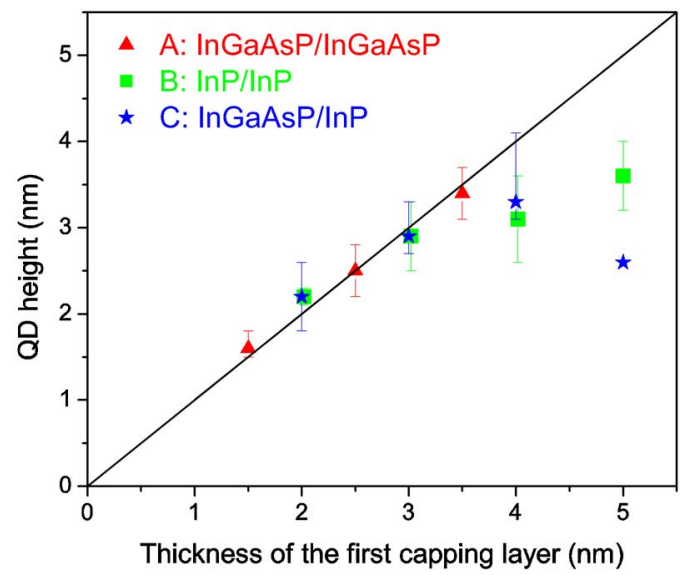

FIG. 4. (Color online) Average QD height in each layer as a function of the nominal thickness of CL1 for the three analyzed samples. The error is taken as the distance to the maximum and minimum values that were measured. The solid curve represents the ideal situation where the dot height corresponds exactly to the thickness of CL1. A significant deviation is observed for thick first capping layers.

fective in this case. ${ }^{21}$ Complementary experiments to clarify this question are still in progress.

All the results are summarized in Fig. 4, in which the average height of the QDs in each layer is plotted as a function of the nominal thickness of CL1 for the three analyzed samples. The solid curve represents the ideal situation where the dot height corresponds exactly to the thickness of CL1. The double capping method works well for first capping layers up to $\sim 3.5 \mathrm{~nm}$, independently of the materials used. This is very important because the desired QD height for $1.55 \mu \mathrm{m}$ applications $(\sim 2.7 \mathrm{~nm})$ lies in that range. No clear differences in height dispersion are observed between different materials, as evidenced by the fact that the error bars in Fig. 4 are on average similar for the different samples in that range of thicknesses. For layers thicker than $\sim 3.5 \mathrm{~nm}$, a reduction in the dot height compared to the thickness of the first capping layer is observed, indicating that the control over the QD height with the DC process is lost for capping layers thicker than that value. This can be understood in terms of a transition from a double capping to a classical (one step) capping process when the first capping layer is thick enough to completely cover the dots. Once the dots are covered, the growth interrupt has no effect on them. Since the height of similar classically capped QDs has been measured to be around $3.5 \mathrm{~nm},{ }^{16}$ this should be the maximum possible height obtained and the DC method should not work for CL1 thicker than that. Indeed, $3.5 \mathrm{~nm}$ is approximately the saturation value observed for thick capping layers in Fig. 4 (except for the special case of $5 \mathrm{~nm}$ in sample $\mathrm{C}$, in which a strong decrease of the QD density is also observed).

In summary, our X-STM measurements show that the double capping method applied to InAs/InP (311)B QDs grown by MBE allows a very accurate control of the QD height when the thickness of the first capping layer is not higher than $\sim 3.5 \mathrm{~nm}$, independently of the material used in the capping layer. For higher values a significant reduction of the QD height is observed. This is explained by the fact that $3.5 \mathrm{~nm}$ is the height of classically capped QDs and therefore, for thicker capping layers the double capping process becomes a classical capping process since the QDs would be completely covered by the capping layer before the growth interrupt.

The authors would like to thank founding from the European Network of Excellence SANDiE (Contract No. NMP4-CT-2004-500101).

${ }^{1}$ S. Fafard, Z. Wasilewski, J. McCaffrey, S. Raymond, and S. Charbonneau, Appl. Phys. Lett. 68, 991 (1996).

${ }^{2}$ H. Marchand, P. Desjardins, S. Guillon, J.-E. Paultre, Z. Bougrioua, R. Y.-F. Yip, and R. A. Masut, Appl. Phys. Lett. 71, 527 (1997).

${ }^{3}$ S. Frechengues, N. Bertru, V. Drouot, B. Lambert, S. Robinet, S. Loualiche, D. Lacombe, and A. Ponchet, Appl. Phys. Lett. 74, 3356 (1999).

${ }^{4}$ P. Caroff, C. Paranthoën, C. Platz, O. Dehaese, H. Folliot, N. Bertru, C. Labbé, R. Piron, E. Homeyer, A. Le Corre, and S. Loualiche, Appl. Phys. Lett. 87, 243107 (2005)

${ }^{5}$ C. Paranthoën, N. Bertru, O. Dehaese, A. Le Corre, S. Loualiche, B. Lambert, and G. Patriarche, Appl. Phys. Lett. 78, 1751 (2001).

${ }^{6}$ K. Ozasa, Y. Aoyagi, Y. J. Park, and L. Samuelson, Appl. Phys. Lett. 71, 797 (1997).

${ }^{7}$ Y. Sakuma, M. Takeguchi, K. Takemoto, S. Hirose, T. Usuki, and N. Yokoyama, J. Vac. Sci. Technol. B 23, 1741 (2005).

${ }^{8}$ G. Saint-Girons, G. Patriarche, A. Michon, G. Beaudoin, I. Sagnes, K. Smaali, and M. Troyon, Appl. Phys. Lett. 89, 031923 (2006).

${ }^{9}$ Q. Xie, P. Chen, and A. Madhukar, Appl. Phys. Lett. 65, 2051 (1994).

${ }^{10}$ N. N. Ledenstov, V. A. Shchukin, M. Grundmann, N. Kirstaedter, J. Böhrer, O. Schmidt, D. Bimberg, V. M. Ustinov, A. Yu. Egorov, A. E. Zhukov, P. S. Kop'ev, S. V. Zaitsev, N. Yu. Gordeev, Zh. I. Alferov, A. I. Borovkov, A. O. Kosogov, S. S. Ruvimov, P. Werner, U. Gösele, and J. Heydenreich, Phys. Rev. B 54, 8743 (1996).

${ }^{11}$ J. M. Garcia, G. Medeiros-Ribeiro, K. Schmidt, T. Ngo, J. L. Feng, A. Lorke, J. Kotthaus, and P. M. Petroff, Appl. Phys. Lett. 71, 2014 (1997).

${ }^{12}$ Z. R. Wasilewski, S. Farad, and J. P. McCaffrey, J. Cryst. Growth 201, 1131 (1999).

${ }^{13}$ R. Songmuang, S. Kiravittaya, and O. G. Schmidt, J. Cryst. Growth 249, 416 (2003).

${ }^{14}$ Q. Gong, P. Offermans, R. Nötzel, P. M. Koenraad, and J. H. Wolter, Appl. Phys. Lett. 85, 5697 (2004).

${ }^{15}$ T. Raz, D. Ritter, and G. Bahir, Appl. Phys. Lett. 82, 1706 (2003).

${ }^{16}$ P. J. Poole, R. L. Williams, J. Lefebvre, and S. Moisa, J. Cryst. Growth 257, 89 (2003).

${ }^{17}$ C. Çelebi, J. M. Ulloa, P. M. Koenraad, A. Simon, A. Letoublon, and N. Bertru, Appl. Phys. Lett. 89, 023119 (2006).

${ }^{18}$ P. Caroff, N. Bertru, A. Le Corre, O. Dehaese, T. Rohel, I. Alghoraibi, H. Folliot, and S. Loualiche, Jpn. J. Appl. Phys., Part 2 44, L1069 (2005).

${ }^{19}$ D. M. Bruls, J. W. A. M. Vugs, P. M. Koenraad, H. W. M. Salemink, J. H. Wolter, M. Hopkinson, M. S. Skolnick, F. Long, and S. P. A. Gill, Appl. Phys. Lett. 81, 1708 (2002).

${ }^{20}$ H. R. Gutiérrez, M. A. Cotta, J. R. R. Bortoleto, and M. M. G. de Carvalho, J. Appl. Phys. 92, 7523 (2002).

${ }^{21}$ Jeong-Sik Lee, Hong-Wen Ren, Shigeo Sugou, and Yasuaki Masumoto, J. Appl. Phys. 84, 6686 (1998). 